\title{
Language as an including or excluding factor in mathematics teaching and learning
}

\section{Sally-Ann Robertson ${ }^{1}$ (D) $\cdot$ Mellony Graven ${ }^{1}$ (i)}

Received: 3 September 2019 / Revised: 5 November 2019 / Accepted: 19 November 2019 / Published online: 10 December 2019

(C) The Author(s) 2019

\begin{abstract}
This article explores the power of language to either include or exclude certain groups of students from genuine opportunities for mathematical sense-making. The substantial increase worldwide in the number of students learning mathematics through a language other than their primary language makes this a particularly urgent issue. This paper focuses on the South African situation, where, because English is widely perceived as the language of opportunity, it is, by grade 4, overwhelmingly the chosen language of learning and teaching. The epistemological and pedagogical consequences of this choice are evidenced in the poor performance of the country's students on national and international assessments of mathematical proficiency. Drawing on research literature around language immersion education models and the extent to which these align with certain key principles of second language acquisition, this position paper motivates for a stronger and more sustained commitment to providing students, particularly those from marginalized and vulnerable communities, with opportunities for becoming both bilingual and biliterate. Empirical data from two South African grade 4 mathematics classrooms are used to illuminate aspects of the mathematical sense-making challenges students and their teachers face without such commitment.
\end{abstract}

Keywords Academic-language development · Bilingual learners · Epistemological access - Inclusive education · Language immersion practices · Mathematical sense-making

\section{Introduction}

In line with the introduction for the Special Issue on inclusive mathematics education, we examine some pedagogical and epistemological implications of mathematics

Sally-Ann Robertson

s.a.robertson@ru.ac.za

1 South African Numeracy Chair Project, Education Department Building, Rhodes University, Grahamstown, Eastern Cape Province 6140, South Africa 
teaching and learning taking place through a second language (L2). Teaching and learning taking place through an L2 is particularly prevalent in former colonial countries and countries with high immigrant populations. The dominance of a single language of power as the medium for education has major implications for access to learning for those who do not speak this language at home and who are often already marginalized in terms of access to social and economic goods.

Research has established across multiple contexts that native speakers of the language of teaching and assessment outperform non-native speakers on mathematics assessments (see Prediger et al. 2019). In this respect fluency in the dominant language of learning, teaching and assessment is a key issue for inclusivity and equity. This said, we note at the outset that this does not imply a deficit conceptualisation of students learning through a L2. Indeed, bi- or multilingualism can have many learning benefits when L2 students' home languages are viewed as 'resources' rather than as 'problems' (after Ruíz 1984; see also Planas and Setati-Phakeng 2014; Planas 2018; Prediger et al. 2019). We note instead that there are major deficiencies with education systems that require a majority of students to learn mathematics in a L2 but fail to adequately support students in becoming academically proficient in that language. We note too that failure to support ongoing and constructive use of students' home languages as additional resources for mathematical sense-making represents further evidence of a deficiency within such systems. At a systemic level, such failures have major implications for inclusivity and equity for L2 students.

\section{Language as core to effective teaching and learning of mathematics}

Working as co-authors from our language education and mathematics education backgrounds, we have been able to 'synergise' across our disciplinary resources in reflecting on the ways in which language issues may make mathematics classrooms more or less inclusive. The second author has worked in the field of mathematics education (as teacher, lecturer, community-based educator and, more recently, as the South African Numeracy Chair involved in research and development in mathematics education with primary school students, teachers, parents and district workers). The first author is an 'out-of-fielder' in the sense that, although she taught primary school mathematics in the early years of her teaching career, she has no tertiary-level mathematics credentials. In her subsequent work as a teacher educator, she specialized in the fields of multicultural education, sociology of education and English second language teaching and learning. She brings her insights from these latter fields to the language/mathematics interface that is the focus of our collaboration in preparing this article.

Interest around interrelationships between language and the teaching and learning of mathematics has increased significantly over the past several decades. Traditionally teacher-centred pedagogies in mathematics education have given way to more studentcentred pedagogies with greater emphasis on students' discursive skills in the mathematics classroom. This has prompted calls for more explicit attention to be given to assisting students in honing their linguistic proficiency in the mathematical discourses needed, for example, to explain, reason, argue and defend their mathematical thinking.

Independently of linguistic and conceptual challenges related to complexities in the language needed to express mathematical thinking, attention is now increasingly turning to issues bearing on language of learning and teaching policy decisions. In 
particular, attention is drawn to the challenges students face when they are denied access to the linguistic resources of their primary language (L1) as tools for learning mathematics and are forced instead to learn mathematics through an L2 in which they as yet have little fluency. This latter aspect provides the impetus for our study.

Gervasoni (2018) notes that 'ensuring that all children thrive mathematically' does not simply relate to well-being at the individual level (in terms of 'future citizenship and opportunities for work and further education'), but 'ultimately [contributes also to] the economic and cultural prosperity of a society' (p. 115). Circumstances requiring students to learn mathematics through a language other than their L1 constitute a threat to their ability to 'thrive' mathematically. It also undermines policy commitments to inclusivity. Equally, however, circumstances which reduce already marginalized students' opportunities to become mathematically proficient in one (or more) of the socalled 'languages of power' too undermine their potential access to an important form of 'cultural capital' (Bourdieu and Passeron 1977) with which to interact in and with a wider mathematics community. Inadequate opportunities for developing mathematical thinking in either language (the primary and/or the powerful) constitute exclusion and are thus, a form of 'symbolic violence' (Bourdieu and Passeron 1977) at both individual and societal levels. Remediating such circumstances points to the desirability of students having opportunities to develop their mathematical proficiencies in more than just a single language.

Language immersion practices, and the risk some lesser versions of such practices may pose to inclusivity, shaped our presentations at the last two Mathematics Education Research Group of Australasia (MERGA) conferences (Robertson and Graven 2018, Robertson and Graven 2019a). The reviewers for our MERGA 2019 position paper indicated this to be an important dialogue to continue. This is the purpose of the present paper.

We refer throughout the paper to language circumstances in the classrooms with which we are most familiar: South African classrooms. We trust, however, that readers from other contexts may find useful parallels in the circumstances of linguistic inclusion/exclusion we describe, particularly given estimates that 'as much as $40 \%$ of the global population does not have access to an education in a language that they speak or understand' (UNESCO Global Education Monitoring Report 2016, p. 1). It has been claimed that South Africa's circumstances represent 'extremes', hence, for instance, Graven's (2014a) opening statement: 'South Africa provides an 'extreme' case of performance gaps between high and low SES learners' (p. 1039). While certainly not the only contributory factor to such performance gaps, the fact of a majority of South Africa's students being schooled through an as yet incompletely mastered L2, without attention given to how their home language can be used as a resource for learning, is a significant challenge to the effective learning of mathematics.

The increase worldwide in the number of students learning through an L2 is partly a function of an unprecedented expansion in global migration: the main drivers being not simply a search for improved socio-economic circumstances but, 'in recent years ... displacement occurring due to conflict, persecution, environmental degradation and change, and a profound lack of human security and opportunity' (McAuliffe and Ruhs 2017 , p. 1). The increase in L2 student numbers is also partly a function of linguistic hegemony. Certain powerful languages have superseded the indigenous languages of many of the world's people. English is a case in point. In many former British colonies, 
and despite its relatively late arrival in these places, English has retained its aura as the language of power and, as such, the language of perceived opportunity. Post-independence, many former colonies selected English ahead of an indigenous language as their main official language for schooling and other governmental purposes, producing the paradoxical situation of people in their own home countries having only limited access to education through their home language/s. This situation pertains South Africa.

South Africa is a multilingual society. It has 11 official languages. Between 70 and $80 \%$ of South African students are taught in their L1 for their first 3 years of schooling (South Africa, Department of Basic Education 2010). After this initial phase, however, a dramatic switch occurs. Despite English being the L1 for less than $10 \%$ of the country's population, it has, by grade 4, become the chosen language of teaching and learning for $80 \%$ of South Africa's school-going population (Department of Basic Education 2010), testament to perceptions around the power of English as the language of opportunity.

South Africa's Language in Education Policy (South Africa, Department of Education 1997), promulgated shortly after the country's 1994 transition to full democracy, mandates School Governing Bodies with making the choice as to which of the country's 11 official languages their school should use as its official language of learning and teaching. Some, Desai (1999), for example, question whether this policy 'errs on the side of allowing too much choice' (p. 46). The progressively assimilationist and monolingual trend in the direction of English flies in the face of the Policy's advocacy of additive bilingualism (namely, ongoing support for students' developing academic proficiencies in their L1 in tandem with their development of academic proficiency in a L2). Failure to observe the principles of additive bilingualism, when coupled with extremely poor outcomes on national and international assessments for literacy and numeracy, has prompted suggestions that English may actually have become a 'medium of destruction' for our country (Bloch 2002). In challenging the fairness of some such assessments, Sibanda and Graven (2018) note that 'access to mathematics learning and successful interpretation of assessments depends to a large degree on understanding the language of learning, teaching and assessment' (p. 11). Some changes do seem to be afoot, however, both in South Africa and elsewhere on the African continent, in recognizing the negative and exclusionary consequences learning through an inadequately mastered language has for educational outcomes. Albaugh (2014) reported, for example, that whereas at independence, 'only nineteen out of fortynine African states (29 percent) were using local languages in primary education, the number has doubled to thirty-eight states (78 percent) doing so currently' (pp. 7-8).

In the following sub-sections, we first link notions of inclusivity in the classroom to issues of classroom language. We then identify key features of different language immersion models and consider ways in which, or whether they align with core principles for supporting L2 acquisition. Our intention for this paper is primarily to make a theoretical contribution, but, recognizing the 'animatory' potential of data from real classroom settings, we share insights from two South African grade 4 mathematics classrooms to highlight aspects of the different language immersion practices observed there. We close with reference to implications relative to language's power to either include or exclude certain groups of students from opportunities for genuine engagement with, and participation in, school mathematics. 


\section{Inclusivity relative to classroom language}

Goal 4 of the United Nations post-2015 development agenda is to 'ensure inclusive and equitable quality education and promote lifelong learning opportunities for all' (2018, p. 6). In some contexts, inclusive education has been associated with the education of children with 'special needs'. South Africa was a case in point, as witness the Education Ministry's acknowledgment that, historically [emphasis added], children with special needs would be those 'learners with disabilities and impairments' (South Africa, Department of Education 2001, p. 7). In broadening the scope of its definition of inclusive education, however, the Ministry noted that inclusive education involved the provision of 'enabling education structures, systems and learning methodologies to meet the needs of all learners' [emphasis added], including needs arising because of, inter alia, 'inappropriate languages or language of learning and teaching' (South Africa, Department of Education 2001, pp. 6-7). For many Black South African students, ${ }^{1}$ school represents their main, sometimes sole, source of exposure to English. This is particularly so in rural and peri-urban areas, where the geographical separation of peoples along racial lines (and linked socio-economic lines) instituted under apartheid remains a feature of the country's lived landscape.

While the United Nations (2018) noted the significant improvement in physical access to education (most particularly in relation to primary school enrolment numbers), questions around equitable opportunities for epistemological access (after Morrow 1994) remain troublesome. By epistemological access, we refer to the opportunity of 'learning how to become a successful participant in an academic practice' (Morrow 1994, p. 40). This relates-perhaps most particularly-to access to some of the more powerful forms of knowledge (amongst which would be included mathematics) and the requisite academic literacies required to maximize students' potential for genuine sense-making around these powerful forms of knowledge. We note that earlier definitions of what was involved in becoming 'literate' tended to foreground mastery of the skills of reading and writing. Newer definitions go much further. Literacy is now viewed more broadly as an ongoing 'developmental process' (Hammond et al. 1992, p. 9); one which encompasses a range of different forms of literacy. In the schooling context, such forms would relate to the kinds of 'literacy demands' and 'literate actions and practices' associated with the various content areas (Castanheira et al. 2001, p. 354).

Several of the world's 'Global South' countries participating in international and cross-national bench-marking assessments of literacy and numeracy have performed poorly relative to other countries. South Africa's TIMSS (Trends in International Mathematics and Science Study) assessments, for example, are cause for concern. The assessment results indicated that ' $61 \%$ of [South African] Grade 5 students could not add and subtract whole numbers, have no understanding of multiplication by onedigit numbers and cannot solve simple word problems, i.e. they cannot do basic mathematics' (Spaull 2019, p. 3). In relation to our paper's focus on language, we

\footnotetext{
${ }^{1}$ At a recent conference, a delegate expressed surprise at some South African presenters' continued use of racial categories in talking about South African circumstances. As we explained to her, South Africa is striving to become a non-racial society, but, because it is important to be able to track progress towards redressing past racial inequities and inequalities, the racial labels 'Black African', 'Coloured', 'Indian' or 'Asian', 'White' continue being used in official documents. For this paper, therefore, where appropriate, we too use these labels.
} 
note that in their formal report on South African grade 5 students' TIMSS 2015 performance, Reddy et al. (2016) identified language as a significant contributory factor to such poor performance, albeit not the only factor at work. These authors report that only $31 \%$ of students in South Africa's TIMSS 2015 cohort 'always or almost always spoke the language of learning and teaching at home', achieving significantly better scores than those whose home language was different from the language used at school (2016, p. 8). Such findings point to the importance of ensuring two things in particular. Firstly, that inclusion of the home language ought always to constitute a legitimate part of school discourse; secondly, that, and especially where there are home/school language differences, ensuring that students' opportunities to develop proficiency in school language/s ought to be prioritized. We intend in the second part of the above 'ought' statement to signal a dual interpretation of 'school language' proficiency (namely, not simply proficiency in the language/s of learning and teaching, but proficiency also in the use of language in the 'academic' context of learning school mathematics). Failure to attend to either of these imperatives almost certainly has exclusionary consequences for some students, for, as Cummins (1999) has suggested, failure to properly promote bilingual students' development in 'school language' has, in many instances, led to deficit assessments of bilingual students' academic capabilities and so contributed to their being 'seriously over-represented in classes for the learning disabled or mildly handicapped and under-represented in classes for gifted and talented students' (p. 5).

Planas and Setati-Phakeng (2014) use the distinction made by Ruíz (1984) between 'language-as-problem', 'language-as-resource' and 'language-as-right'. Increasingly research and language policy are moving away from focusing on the 'language-asproblem' orientation, and drawing instead on the latter two orientations: 'language-asresource' and 'language-as-right'. We particularly welcome the move towards language-as-resource (both in policy and in research), precisely because it challenges deficit assessments of students who are not proficient in the language of instruction. Such deficit discourse frames students who are not proficient in the language of instruction as 'having the problem'. This may then result in reduced opportunity to learn for those seen to 'be deficient'. For example, de Araujo's findings (2017) show that secondary mathematics teachers' selection of less cognitively demanding tasks were guided by their beliefs about limitations in L2 students' linguistic abilities. Robertson and Graven (2019b) too showed how use of English only in a grade 4 class of first language isiXhosa students constrained the mathematics teacher's efforts to encourage exploratory talk, with students making statements of mathematical 'fact' rather than providing reasons why. This restricted the students' opportunities for deepening their conceptual understandings of mathematical ideas.

Prediger et al. (2019) remind us that 'language is a major learning medium used for communicative and epistemic purposes in mathematics classrooms', making it imperative that language 'become a learning goal also, in mathematics classrooms' (p. 11) [italics in the original]. Shifting the discourse from a language-as-problem orientation towards a language-as-resource orientation and then translating this into practical pedagogical implications for mathematics teaching are complex (Barwell 2016). It requires a great deal of systematic thought and professional preparation. If mathematics teachers do not have strategies in place for using students' own linguistic resources, students with little fluency in the mandated language will experience language as a 
barrier to learning. As we note in our next sub-section, however, exploring ways for making language a learning goal in the mathematics classroom is not generally a prominent feature of mathematics teacher education (Jordaan 2011; Edmonds-Wathen 2017). This said, there are some well-researched principles that can be drawn on at a broad level, and we will foreground some of these in the concluding section of the paper where we provide our recommendations for 'language-responsive mathematics teaching' (Prediger 2019, p. 1).

\section{Different language immersion models relative to opportunities to become both bilingual and biliterate}

Language immersion programmes have generally come about in response to societal challenges ranging from 'repairing injustices committed in the past as a result of colonization' [in relation to indigenous languages] to responding to increasing social diversity and the need to 'find ways to cohabitate and collaborate with each other' (Cammarata and Tedick 2012, p. 251). It was precisely a desire for this latter sort of opportunity that provided the impetus for the launch in the mid-1960s of an experimental language immersion programme in Canada's Quebec Province. The programme was a result of pressure from a group of English-speaking parents for the setting up of a 'home-school language switch' programme (Melikoff 2018). The parents wanted their children to become equally fluent and academically proficient in Quebec Province's official language: French. The success of this experimental programme was instrumental in the emergence of numerous other language immersion programmes (in Canada, and elsewhere).

We noted in our MERGA 42 paper that a "significant 'buy-in' factor" contributing to the success of Quebec Province's experimental immersion programme was that the languages involved (French and English) were of equivalent international status (Robertson and Graven 2019a, p. 605). This does not always pertain in other contexts. In South Africa's case, the indigenous African languages struggle to 'compete' with English in terms of their social, educational, political and economic traction within and beyond the country's borders. As 'minority' languages, they risk being overshadowed, even completely replaced, by the more prestigious language of power, social status and commerce (English) — which is also a widely spoken international language. The language statistics for South African classrooms we provided in an earlier subsection of this paper give clear evidence of the power of socio-political perceptions and the forces these fuel. Despite the post-apartheid language in education policy's commitment to promoting multilingualism, and its recognition that previous language policies 'affected either the access of the students to the education system or their success within it' (South Africa, Department of Education 1997, p. 1), English is the language a majority of South African students, through their parents, have 'bought into'. This is not to imply indifference on the part of African parents, however, regarding the status of their own languages in the school context. Exclusion of students' home languages from classrooms denotes, as Cummins (2001) observed, 'devaluation' of an important aspect of students' identity (p. 651). In responding to a suggestion that parents did not mind if isiXhosa was spoken only in the home and not the classroom, an IsiXhosa-speaking father replied: 'That would not be true at all. We do want English. If 
our children go to a township school, they come out and can't get a job because they don't know English well enough. But we're happy if they know English and Xhosa, because that's their culture, and they shouldn't lose it' (cited by Bloch 2002, p. 78). This father's comment is relevant to a point we emphasized in our MERGA 42 paper (Robertson and Graven 2019a), namely that an ideal language immersion programme would develop students to be bilingual as well as biliterate. Such programmes would aim at developing in students not simply an ability to speak two languages fluently but to be literate in both languages (to be able to use both languages fluently in engaging with curriculum content). Such programmes would thus, by definition, be additive: the learning of a L2 would not involve any loss of a student's primary language. Both languages would be supported in ways that helped students develop linguistic and literacy proficiencies in both languages to levels 'commensurate with curriculum content demands' (Robertson and Graven 2019a, p. 604). Quebec's experimental French/English immersion programme arose as a direct result of parental pressure for this desired higher-level additive form of bilingualism. English being a minority language in Quebec, English-speaking parents recognized the distinct social (integrative) and economic (future employment) benefits to be derived from their children's becoming equally literate also in French (Melikoff 2018).

We have included in other publications (for example, Robertson and Graven 2019b) our diagram illustrating some common models of bilingual education and the extent to which they lean towards either an additive or a subtractive form of bilingualism. In Fig. 1, below, and, with some minor adaptations, we again present this diagram.

Models D and E, and to a lesser extent C in Fig. 1, would meet the 'additive' criterion. Heugh, an applied linguist at the University of South Australia, has been involved in extensive and large-scale research around the importance of mother tongue learning on the African continent. As she notes, well-structured mother-tongue-based multilingual programmes

... are likely to result in higher retention and lower grade repetition. They also do not cost a fortune. Investment in such programmes in Africa at the moment is usually less than $2 \%$ of a country's education budget - and is recovered within five years. (Heugh 2017, pp. 2-3 of 4, online article).

It takes time, however, to achieve these positive outcomes. Findings from a UNESCO study of 25 African countries indicate that, even in well-resourced contexts, it takes children 6-8 years to become adequately proficient in an 'international' L2 (i.e. not one of their local indigenous languages) to be able to then use this language effectively for academic purposes (Heugh 2017; see Alidou et al. 2006). We later refer to similar findings in non-African contexts (Collier and Thomas 2017; Cummins 2008). For the present, we wish simply to draw attention to Heugh's observation in relation to the African research that 'a child's mother tongue or local language is indispensable as the main medium of instruction [emphasis added] during these six to eight years' (2017, p. 2 of 4 , online article). We note that Model C of Fig. 1 represents only the bare minimum relative to this recommended 6-8-year time-frame. And, we note also that Models A and $\mathrm{B}$ are the models predominantly operating in South African classrooms, including in the two South African grade 4 mathematics classrooms we report on in the penultimate section of this paper. 


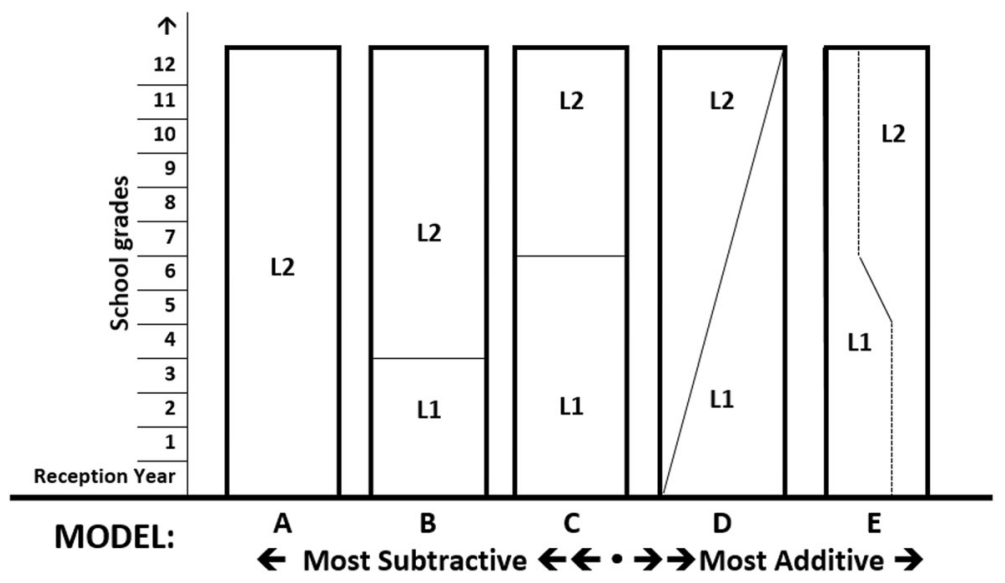

Fig. 1 Some models of bilingual education

As Fig. 1 illustrates, A and B represent the most subtractive of the models shown here, Model A being the most subtractive. Here, students enter an L2 environment from the start and continue in this environment for their entire schooling. Insofar as 'both language and subject matter are unfamiliar', and little, if any, provision may be made for systematic and ongoing development of the L1 as an additional sense-making resource, this model of bilingualism is reflective of 'submersion' rather than 'immersion' (Skutnabb-Kangas 1990, p. 21). Some label it the 'sink-or-swim' approach (see, for example, Cummins 2007, p. 165). It is an approach which, distressingly, as Skutnabb-Kangas and McCarty (2008) note, may even make bilingual students 'feel ashamed of their mother tongues, or at least to believe in the superiority of the language of instruction' (p. 12).

Model B, an 'early exit' model, is only marginally less subtractive or 'submersive'. Macdonald (2002), researching in the South African context, challenged this early transition by comparing it to expecting Black African students to 'swim up a waterfall'. The magnitude of such challenges is manifestly greater for 'at risk' students. It increases the likelihood of their exclusion from opportunities for educational success, for, as Heugh notes, 'successful education, especially [emphasis added] for vulnerable and marginalised communities, cannot occur unless children understand the language/s through which it is provided' (2017, p. 4 of 4 , online article).

Mathematics teachers working in immersion contexts face the dual responsibility of teaching mathematics while supporting their bilingual students' ongoing development in the language of teaching and learning. This requires a considerable balancing act. Teachers equally well-versed in both content and language teaching are probably quite rare. 'Research strongly suggests that most immersion teachers lack pedagogical content knowledge when it comes to language [and, furthermore] what it takes for immersion teachers to systematically and meaningfully integrate language in the context of their content teaching has yet to be fully understood' (Cammarata and Tedick 2012, p. 254).

Much work on clarifying links between language and mathematics has been undertaken by the mathematics education research community over the past several decades. Some few notable examples across different contexts include the work of African 
academics (Setati and Adler 2000; Setati et al. 2009), Australasian academics (Clarkson 2009; Edmonds-Wathen 2017; Meaney et al. 2017; Jorgensen 2018), European academics (Planas 2018; Prediger 2019) and academics working in the USA (see, for example, Moschkovich 2010; Civil 2018).

Bearing on the points cited above from Cammarata and Tedick (2012), we note in the Australian context, Edmonds-Wathen's (2017) observation that many teachers responsible for teaching Aboriginal students in the Northern Territory lack specific qualifications for teaching English as an additional language but that support for their endeavours in this regard is expected to come from the schools rather than through explicit state support for their ongoing professional development in L2 teaching. Edmonds-Wathen notes further that a shortage of suitably qualified teachers has meant that inexperienced and underqualified teachers often find themselves forced to 'learn on the job' (2017, p. 37). A similar challenge confronts South Africa's teachers. Jordaan (2011) noted that a prime cause for South African students' underachievement was that 'the pivotal role of language in education is neglected in curriculum and in teachertraining programmes, resulting in limited language awareness, and consequently inadequate teaching methods that lead to language difficulties across all curriculum areas' (p. 79). Jordaan (2011) continued by noting this to be 'a problem irrespective of whether English or one of the African languages serves as the medium of instruction, or is the subject of study' (p. 79).

Even experienced mathematics researchers, many of whom are themselves bi- or multilingual, may have a sense of struggle when moving beyond the borders of their disciplinary area in seeking to further deepen their insights around language/ mathematics issues. Moschkovich (2010), having shared the fact of her own multilingual background (Spanish, Portuguese, Idisch (Yiddish) and English), referred as follows to the demands of engaging in inter- and cross-disciplinary work: 'While I remained grounded in my own field, I was using perspectives from fields in which I had little formal training, such as bilingualism and second language acquisition. ... I found that I faced several challenges ... but I also encountered many useful resources' (pp. xvi; 1-2).

\section{Second language acquisition and literacy development in and for an inclusive mathematics classroom}

Mercer and Howe (2012) report increasing research-based evidence demonstrating that 'talk amongst teachers and students, if of the right quality, can be a powerful motor for the development of reasoning and the improvement of academic performance' (p. 13). Much significance lies in the phrase 'of the right quality', but, in relation to bilingual students, the initial step towards such quality has to be the actual acquisition of the L2. UNESCO's Policy Paper 24 (2016) makes the incontrovertible point that not speaking the language of the classroom 'frequently holds back a child's learning, especially for those living in poverty' (p. 1). We have noted that, worldwide, many children are in this vulnerable position. This points to an urgent need to extend-beyond the borders of those communities expressly involved in L2 teaching - an increased awareness of some of the core principles of L2 acquisition (SLA), particularly for those contexts where the L2 is needed for academic purposes. 
From the extensive SLA literature-base, we have chosen to focus on the competing ideas of just two contributors to the field: Krashen (2009) and Swain (1985, 2006). In then moving across into the area of literacy development in and through an L2, we have chosen to draw on the work of Cummins. His insights continue to contribute significantly to understandings around the important differences between 'everyday' language and the more precise and 'academically oriented' kinds of language generally required in classrooms.

Language skills fall into two main categories: receptive and productive. In terms of explaining SLA, Krashen places the greater emphasis on the receptive skills (listening and reading), and on the role comprehensible input plays in SLA. Swain, on the other hand, while not gainsaying the importance of comprehensible input, argues that what most strongly pushes bilingual students towards communicative competence in an L2 is the requirement that they actively communicate - produce output that is comprehensible to others - in that L2. (We note some parallel here to the shift in emphasis in promoted mathematical pedagogies from students learning by listening to mathematical language spoken by the teacher to producing mathematical language in their sensemaking process.)

For Krashen (2009), SLA proceeds along essentially the same lines as L1 acquisition. Bilingual students need plenty of exposure to the L2; they need an unthreatening, encouraging environment so that their affective filters remain lowered; and they need an incentive to 'make meaning' of the input (i) being communicated. Two further important elements of Krashen's SLA theory are firstly that the L2 to which bilingual students are exposed be just a little beyond their current levels of proficiency $(i+1)$, thereby requiring some cognitive effort from them in unpacking the meaning; and, secondly, that there needs to be an authentic reason (or incentive) for unpacking this meaning. A good way in Krashen's view of achieving both these elements is by having the target L2 as the main language of teaching and learning. The desire to learn, to participate in classroom interactions, is what motivates students to pay attention and to genuinely engage with their teacher/s in negotiating meaning to help make the input ever more comprehensible. Krashen views L2 learning as an essentially 'subconscious' process in which the desire to comprehend input, rather than a focus on linguistic rules, is the main driver of SLA.

For Swain (1985), Krashen's comprehension-driven account of SLA is altogether too simplistic, particularly for contexts where bilingual students are struggling to establish agency over their academic learning through an L2. Noting that comprehension of an L2 and production of that L2 are two quite different processes, Swain (1985) argues that the productive skills (speaking and writing) are more central to the L2 acquisition process. It is the syntactic processing involved in producing the L2 that forces students to pay attention to the 'form' (vocabulary, syntax, etc.) of the L2 (Swain 1985). To build up their L2 proficiencies, students therefore need opportunities to practise syntactic processing, as opposed to mere semantic processing.

Swain (2006) uses the term 'languaging' to encapsulate the act of using language to mediate cognitively complex ideas. Bilingual students' developing understanding of L2 'form' and their being able to put this to use in producing comprehensible output is what best helps them align their L2 languaging with the academic requirements of, in the present context, the mathematics classroom. A teacher's role in this process is to provide frequent and constructive feedback to students on how well they are doing at using their L2 to convey their intended meanings. 
In recent publications, Swain makes more mention also of the importance of students' L1 for the SLA process. Citing Vygotsky's point that the L1 acts as a 'mediator between the world of objects and the new language' (p. 106), Swain and Lapkin (2013) argue for 'principled use' of the L1 as an essential additional cognitive resource in grappling with the challenges of communicating ideas in the L2. This approach has been argued for decades. Moll, drawing on Vygotskian thinking, argued, for example, that bilingual education practices needed to move away from an emphasis 'solely on remediating students' English language limitations, ... [and towards] utilizing available resources, including the children's or the parents' language and knowledge, in creating new, advanced instructional circumstances for the students' academic development' (1992, p. 23). ${ }^{2}$

Almost every bilingual student of school-going age has a well-developed L1 system from which to draw in his or her classroom sense-making endeavours, and Cummins is amongst those who have long encouraged recognition of the important role bilingual students' L1s play in L2 academic settings. Although aspects of his early work attracted some criticism, we find his ideas to be theoretically and pedagogically helpful. They are widely cited in literature around ways for mediating some of the many barriers minority group bilingual students face. Two aspects of his work are especially pertinent to South African circumstances: firstly, his clarification of differences between 'everyday' and 'academic language' registers and that it takes bilingual students significantly longer to develop L2 competence in the latter; secondly, his highlighting of the vital role students' L1 literacy proficiencies can play in developing their academic competence in L2.

Integral to the success of a language immersion programme is the degree to which bilingual students receive the support needed to develop proficiencies in their L2 beyond that required for everyday communicative purposes. The cognitive and linguistic demands of communication relating to curriculum content are generally much higher, and Cummins's acronyms BICS and CALP have been widely used in helping to distinguish between 'everyday' communicative competence and the more linguistically and cognitively demanding 'academic' communicative competence. BICS ('basic interpersonal communicative skills') refers to the 'conversational fluency' (Cummins 2008 , p. 71) needed for most everyday-type verbal interactions at the interpersonal level. CALP ('cognitive academic language proficiency') refers to the language needed for engaging in abstract, context-reduced ways with texts (both verbal and written) encountered in academic settings. In relation to mathematics, Moschkovich (2010) described the 'language of mathematics' as involving 'the communicative competence necessary and sufficient for competent participation in mathematical Discourse practices' (p. 3).

Cummins identified BICS and CALP as being 'conceptually distinct', and thus not 'reducible one to the other' $(1999$, p. 2). A teacher unaware of this may assess bilingual students' linguistic proficiency on the basis of BICS evidence. Should these students then struggle to express their more formalized mathematical thinking in the L2, the teacher may label them 'learning disabled' (Cummins 1999, p. 5). Work around the BICS/CALP distinction has helped to draw attention to the 'ways in which educators'

\footnotetext{
${ }^{2}$ Moll is perhaps best known for his 'funds of knowledge' work (Moll 2015) whereby he advocates culturallyresponsive pedagogies; pedagogies which, by their very definition, are inclusive.
} 
assumptions about the nature of language proficiency and the development of L2 proficiency have prejudiced the academic development of bilingual students' (Cummins 2008, p. 81). Developing academic language competence, as Cummins has repeatedly pointed out, takes significantly longer than does developing social language competence. It is important that teachers recognize the differences between 'the surface or conversational aspects of children's language and the deeper aspects of proficiency that are more closely related to conceptual and academic development' (Cummins 1994, p. 37) and recognize also that - even in optimal circumstances - it may take 5-7 years to develop CALP in an L2, as compared to the 6 months to a year it takes to develop L2 BICS (Collier and Thomas 2017; Cummins 2008).

There are generic aspects of academic proficiency that transcend languages. Cummins and Swain (2014) note that it is 'more difficult to learn initial academic skills through the second language than through the first' (p. xv). It may therefore be more effective if a significant amount of initial literacy and numeracy development is attended to in students' L1 for subsequent transfer across into the L2. Failure to provide support for the ongoing development of bilingual students' academic proficiency in their L1 reduces the proficiencies available for transfer across into their L2. If, for example, a child knows how to decode text in L1, there would be no need to re-master this skill in L2. If a child has grasped the concept of 'one quarter' being bigger than 'one eighth' in L1, there would be no need to re-learn this mathematical fact in the L2; all that would be needed here would be a new set of linguistic labels. If a child knows in L1 that being asked to 'explain' something is different from being asked to 'justify' something, there would be no need to re-learn in the L2 that these represent different task requirements. These are examples of what Cummins (2005) describes as constituting 'common underlying proficiencies'. Figure 2, below, seeks to show that while surface features of different languages may vary, the potential exists for conceptual overlaps in the cognitive elements underpinning particular literate and numerate practices or the particular sets of ideas relating to these knowledge areas.

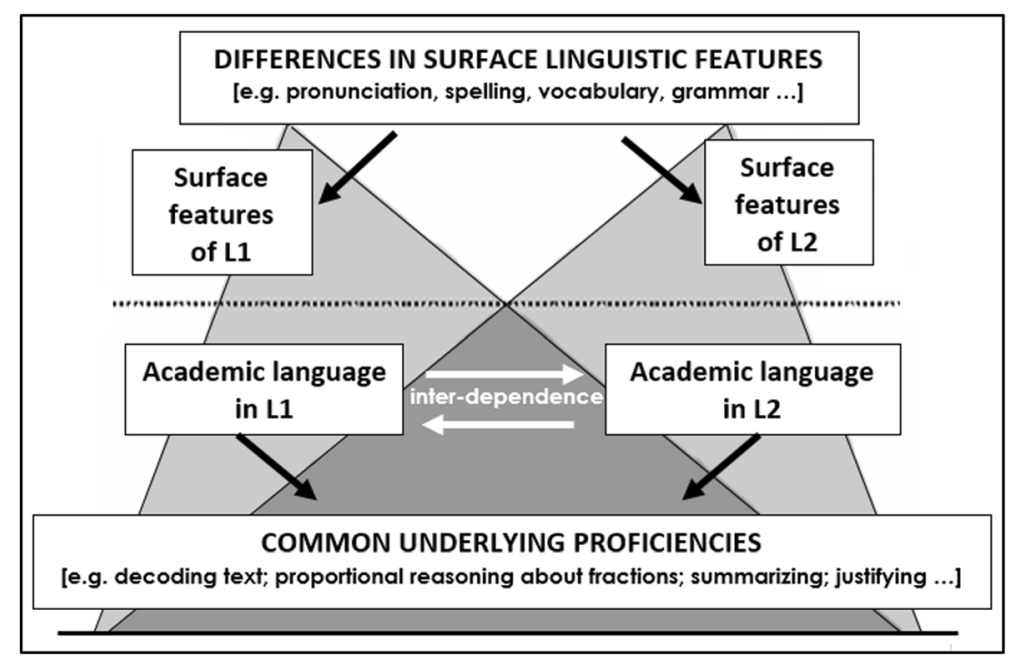

Fig. 2 Cummins's 'dual iceberg' representation of the potential for cross-linguistic transfer (2005, p. 7, adapted with Cummins's permission) 
We conclude this sub-section with Cummins's reflections on the inequitable linguistic circumstances which continue to undermine South Africa's post-Apartheid redress endeavours.

An effective educational response to the underachievement of rural and township students in the South African context will involve expanding the instructional space to include students' and teachers' multilingual repertoires together with explicit instruction designed to demystify how academic language works. (2015, p. 278).

\section{Language immersion practices in two South African mathematics classrooms}

We now provide insight into language practices in mathematics classrooms in two South African schools: one where students' L1 is excluded from the classroom; the other where it is given space, albeit that the teacher fears that in so doing, she is acting illicitly. The grade 4 mathematics classroom data we use to animate our further discussion come from assessment data (local and national), from lesson observation, and from interviews with two mathematics teachers: Ms. M and Ms. P (pseudonyms chosen by them).

Both teachers work in what are termed 'township schools', 'township' being an apartheid-era label used to refer to urban residential areas designated for 'non-whites'. The term continues to be used today and generally refers to places located on the periphery of towns and cities. Many townships are poorly resourced. Many are little more than shanty towns. Students at Ms. M's and Ms. P's schools, and particularly at Ms. P's, come from less-affluent backgrounds. Statistics South Africa's most recent release of national data on poverty (2019a) indicates that almost half $(49.2 \%)$ of the country's adult population lives below the poverty line. In the Eastern Cape Province, which is where Ms. M's and Ms. P's schools are located, the adult poverty rate was assessed at $67.3 \%$. In terms of food security, 1.7 million South African households are recorded as 'experiencing hunger' (Statistics South Africa 2019b). Statistics South Africa's report notes that 'whilst South Africa is food secure at national level, the country is still food insecure at household level as not all households have access to adequate food' (unpaged, online article). Referring to this painful reality in relation to many of her students, Ms. P remarked: "The kid, when he or she is in the class, she's not thinking of what you are teaching. She is thinking, 'What am I going to eat at home?"' (Robertson 2017: interview data).

Graven (2014a) in her discussion of links between poverty and mathematics performance in South Africa notes that genuine deficits deriving from poverty tend to extend into deficit discourses around 'what is considered possible for low SES students' ( $\mathrm{p}$. 1034). Lowered expectations then deprive students of 'opportunities to learn at higher levels' (Graven 2014a, p. 1043). A 'dumbing down' or simplifying of the mathematical tasks sets in motion a self-fulfilling prophecy situation which 'strips individual learners of their agency’ (Graven 2014a, p. 1043). (See, also, Westaway 2019 and Westaway and Graven 2019 for further discussion around some South African primary teachers' 
lowered expectations for certain groups of students.) Reduction of cognitive challenge flouts two important points made by Hodge and Cobb (2019): firstly, that 'mathematically rigorous tasks are critical in supporting instructional practices that are equitable in terms of student learning opportunities'; secondly, that 'issues of access are especially important in the case of students who are members of historically underserved groups and can have a profound influence on their future educational and economic opportunities [emphasis added]' (p. 870).

In terms of students' linguistic access to mathematics, or lack thereof, it is interesting to note the language policy choices made by Ms. M's and Ms. P's schools. Ms. M, Ms. $\mathrm{P}$ and all of their students are native speakers of isiXhosa, the indigenous African language spoken by just over three-quarters of the people living in the Eastern Cape Province. Relative to the models represented in Fig. 1, above, Ms. M's school is a Model A school. It practises a 'straight for English' policy, in other words, a subtractive submersion model. The school prides itself on being an English-medium school. Use of isiXhosa during lessons is discouraged. IsiXhosa is taught as a subject but, given the schools 'English-medium' status, is - paradoxically_taught as the students' 'first additional language' (this, notwithstanding that it is their home language). In terms of official designations, and in a tangled policy anomaly, English is then designated as these students 'home' language. Observation data reveal that Ms. M adhered quite strictly to the 'straight for English' requirement during her mathematics lessons. Ms. P's school, relative to the models represented in Fig. 1, is a Model B school; in other words, it has an 'early exit' language policy. Students complete their first 3 years of foundational phase learning through the medium of isiXhosa. English is taught alongside as a subject. In 4th grade the school begins a formal transition across into English as the dominant language medium, though lesson observation data reveals that Ms. P. continued to make extensive use of isiXhosa. Here is how she explained this extensive use of isiXhosa:

I am supposed to teach them in English, but they do not understand. ... So - most of the time, I speak Xhosa - the one that they understand. ... They are supposed to be taught in English ... so I'm supposed to speak English, but I cannot do otherwise. (Robertson 2017: interview data).

While Ms. P's repeated use of 'supposed' indicated a sense of discomfort on her part, it was, in fact, an indication that she had not been made sufficiently aware of the 'additive bilingual' aspect of South Africa's Language in Education Policy. In this, she is by no means unique. Probyn, for example, has documented other South African teachers' sense of having acted illicitly in drawing on their students' L1s as additional sensemaking resources in L2 teaching and learning contexts (see Probyn 2009, 2015). An encouraging recent development at Ms. P's school has been its selection for a provincewide trialling of an extension of the period of mother-tongue-learning (isiXhosa) up to grade 4, and, subsequently, grade 5 (N. Baart, Provincial Subject Advisor, Department of Basic Education (Eastern Cape Province), personal communication, July 8, 2019).

Both Ms. M and Ms. P expressed concern that, come grade 4, their students' foundational mathematical knowledge was not yet at the expected level. Here, for example, are two remarks from Ms. M. While we would not claim that her students' difficulties in mathematical understanding are entirely linguistic in origin, we remain 
convinced that the school's straight for English policy is a significant contributory factor.

The basics aren't there. ... In grade 4, I know that at least this, and this and this should have been covered in the Foundation Phase. But I find that it's not there. So it means that I have to go back to the Foundation Phase maths, and try to help them. ... If I say they are in grade 4, they should be knowing this and this and this ... [but then] I can see they do not understand, I have to go back. (Robertson 2017: interview data).

And then in a subsequent interview she revisited this, commenting:

I'm in the grade 4 class [but] it's as though I am teaching to the grade $2 \mathrm{~s}$.... You find that, I mean, one place, one exercise is done maybe over 2 days. Same exercise, simple exercise, not even a long one - a short one, is done over 2 days. I think I'm going nowhere. I'm doing nothing. Because I think, 'How can I move on when they don't understand?' Sometimes I think it's easy. But to them, it's not easy, and then you find that one or two learners have mastered it, and what do I do? Ow! I feel like I'm lost. I still have to find ways. What can I do? (Robertson 2017: interview data).

Along similar lines, Ms. P explained that she often found she needed to back-track to earlier grade-level work with her grade 4s:

I will not lie. It's not easy because I start from grade 3 work because most of the work they have not done in ... in the foundation phase. So that work takes time. I start from the grade 3 work, and start from grade 4 afterwards. (Robertson 2017: interview data).

What we find interesting, however, on closer analysis of Ms. M's and Ms. P's comments, is that Ms. M claims a greater backlog in her students' foundational mathematical knowledge than does Ms. P: 2 years as compared with one. Accepting the well-established links between poverty and school performance, this discrepancy becomes the more interesting. Ms. P's school serves a much poorer community than does Ms. M's. A majority of the parents of Ms. M's students are employed, albeit that many earn only at the minimum wage level. This is what makes it possible for her school to charge a nominal annual school fee (a little below US\$100). A majority of the parents of Ms. P's students depend on social welfare grants, and her school is a designated 'non-fee-paying' school.

Ms. $P$ indicated that many of the problems her grade $4 \mathrm{~s}$ experienced were a result of their limited mathematical vocabulary in English. She described some of the ways in which she had worked towards strengthening the students' mathematical vocabulary.

What I did was I chose the words from the mathematics language and then described them on a chart. If I say 'altogether', they must know that it's a 'plus' you use a plus sign. If you say 'left', they do not know which operation this should use. So it's vocabulary that is the problem. ... For example, the problem 
solving, they will reach the situation, then they do not know what to do because of that vocabulary that is limited to them. So, if it is said, 'How much did they get altogether?', they do not know what 'altogether' means, so I must translate it in Xhosa. (Robertson 2017: interview data).

Ms. P mentioned a particular regret she had was that when her grade 4 students came to write their Annual National Assessments for Mathematics, class teachers were barred from being present to mediate the 'unpacking' of the task questions: 'They do have the understanding of what is going on, but the question is their problem'. (Robertson 2017: interview data).

As Table 1, below, indicates, neither Ms. M's nor Ms. P's schools' grade 4 classes performed especially well in the country's Annual National Assessments for Mathematics. Ms. M's students scored slightly above both the provincial and national grade 4 averages in mathematics; Ms. P's school scored below these averages.

Data derived from South African Numeracy Chair Project Database ${ }^{3}$ (2014); and from South African Department of Basic Education (2014, pp. 9, 52).

The Annual National Assessments have been controversial for a number of reasons which lie outside the scope of the present discussion. One reason for dissatisfaction, however, revolves around language of assessment issues. As indicated in the introductory section of this paper, by grade $4,80 \%$ of South Africa's students are officially learning through the medium of English. This being so, they are also assessed in English. As Sibanda (2017) and Sibanda and Graven (2018) note, however, assessment in a language in which a majority of students as yet lack proficiency cannot be seen to provide valid evidence of students' capabilities.

Problems have arisen even in instances where assessment of students' mathematics performance has been through an indigenous African language. The general practice is for assessment papers to first be set in English and then 'versioned' (translated) into the other 10 official languages. Because South Africa's indigenous African languages have yet to be fully standardized, some disagreements arise during the 'versioning' process. We were made party to a small example of such disagreement. We have included reference to this example in an earlier article (Robertson and Graven 2015), but briefly repeat the gist of it. It was a comment from Ms. P's principal that drew attention to this example. During one of the South African Numeracy Chair's professional development workshops, the principal expressed reservations about the wording in one of the isiXhosa versioned grade 4 Annual National Mathematics Assessment papers. This has to do with the translation into isiXhosa of the word 'symmetry'. To follow-up on this, we approached a colleague in our University's African Language Studies Division. The isiXhosa equivalent that had been coined by the assessment translators was bolingano-macala. Our African Languages colleague was not convinced that this coining was a valid reflection of the mathematical conceptualization of 'symmetry' (as in 'a symmetrically-sided figure'). More damningly, however, she expressed serious reservations about the very principle of coining new words when setting up an

\footnotetext{
${ }^{3}$ The South African Numeracy Chair Project (SANCP) collects data across all participating schools. While the anonymity of individual schools is maintained, SANCP's rich database is reported on and shared in various relevant quarters (for example, with funders, and with the broader South African Numeracy Chair Community of Practice forum).
} 
Table 1 Mathematics Annual National Assessments scores (2014): some percentage ranges for Ms. M's and Ms. P's grade 4 students

\begin{tabular}{|c|c|c|c|c|c|c|}
\hline & \multicolumn{3}{|c|}{ Ms M's school } & \multicolumn{3}{|c|}{ Ms P's School } \\
\hline Percentages & $\begin{array}{l}\text { Learner } \\
\text { no's }\end{array}$ & $\begin{array}{l}\% \text { of } \\
\text { learners }\end{array}$ & $\begin{array}{l}\text { Learners } \\
\text { below/ } \\
\text { above } 50 \%\end{array}$ & $\begin{array}{l}\text { Learner } \\
\text { no's }\end{array}$ & $\begin{array}{l}\% \text { of } \\
\text { learners }\end{array}$ & $\begin{array}{l}\text { Learners } \\
\text { below/ } \\
\text { above } 50 \%\end{array}$ \\
\hline $0-30$ & 24 & 36.9 & \multirow{3}{*}{$49(75.4 \%)$} & 55 & 63.2 & \multirow{3}{*}{$80(91.9 \%)$} \\
\hline 31-39 & 10 & 15.4 & & 15 & 17.2 & \\
\hline $40-49$ & 15 & 23.0 & & 10 & 11.5 & \\
\hline $50-59$ & 8 & 12.3 & \multirow{3}{*}{$16(24.6 \%)$} & 3 & 3.4 & \multirow{3}{*}{$7(8.0 \%)$} \\
\hline $60-69$ & 5 & 7.7 & & 2 & 2.3 & \\
\hline $70+$ & 3 & 4.6 & & 2 & 2.3 & \\
\hline $\mathbf{n}=$ & \multicolumn{3}{|c|}{65 (no absentees) } & \multicolumn{3}{|c|}{87 (+8 absentees) } \\
\hline School average & \multicolumn{3}{|c|}{$37.9 \%$} & \multicolumn{3}{|c|}{$27,3 \%$} \\
\hline Provincial average & \multicolumn{6}{|c|}{$34.8 \%$} \\
\hline Differential & \multicolumn{3}{|c|}{$+3.1 \%$} & \multicolumn{3}{|c|}{$-7.5 \%$} \\
\hline National average & \multicolumn{6}{|c|}{$37 \%$} \\
\hline Differential & \multicolumn{3}{|c|}{$+0.9 \%$} & \multicolumn{3}{|c|}{$-9.7 \%$} \\
\hline
\end{tabular}

assessment task. As 'a new coinage', it would be 'unfamiliar [and] even more so to 8/9 year olds', she wrote; adding, 'My belief is that it is wrong to coin new words for assessments. The students would not have used these in the general learning' (P. Maseko, e-mail communication, September 25, 2014).

As part of its impact assessment strategy, the South African Numeracy Chair Project conducts its own assessments of the developing proficiencies of students attending the schools constituting part its 'community of practice' (after Lave and Wenger 1991). Both Ms. M's and Ms. P's schools belong to this community. An assessment instrument based on one developed by Askew et al. (1997) was used to assess students' proficiency levels against three of Kilpatrick, Swafford and Findell's five strands of mathematical proficiency (National Research Council 2001). While we are mindful that the assessment evidence we use in support of the following claim has to be seen as tentative, we believe that Ms. P's bilingual language practices may account in part for her students' marginally better levels of mathematical proficiency as measured on the Numeracy Chair Project's instrument, and as compared with other schools in the same cohort (Table 2, below).

Despite their generally more favourable socio-economic circumstances, as the Table 2 data show, it was only in the conceptual understanding category that Ms. M's students scored higher than did Ms. P's. This calls for further investigation and reflection on our part. We tentatively suggest, however, that this may be partly due to changes in Ms. M's pedagogy deriving from her participation in the South African Numeracy Chair Project's activities, including its Numeracy Inquiry Community of Leader Educators programme (NICLE). Whereas Ms. P joined NICLE in the fourth of its 5-year cycle, Ms. M was a member from the programme's inception (2011). This research and development programme focused on 'supporting Grade 3 and 4 numeracy and mathematics teachers in developing foundational knowledge of learners (not achieved in earlier grades)' (Graven, 2015, p. 5). Table 3, below, shows the South African Numeracy Chair Project's mathematical proficiency assessments for Ms. M's 2011 cohort of students as compared to her 2014 cohort. 
Table 2 Ms. M's and Ms. P's grade 4 students' average percentage scores on the South African Numeracy Chair Project's mathematical proficiency assessments (2014)

\begin{tabular}{lllll}
\hline & Conceptual understanding & Strategic competence & Adaptive reasoning & Overall average \\
\hline Ms M's students & 61 & 25 & 41 & 42.3 \\
Ms P's students & 52 & 34 & 64 & 50 \\
$\begin{array}{l}\text { Project cohort } \\
\text { students }\end{array}$ & 51 & 25 & 29 & 35 \\
\hline
\end{tabular}

Data derived from SANCP Database 2014

Table 3 indicates a cross-cohort improvement against the three strands assessed, a factor which contributed to positive external impact assessment reviews of the South African Numeracy Chair's Project activities and subsequent decisions by funders to support a further 5-year cycle of the Chair. A mid-term external review report in 2014 noted that the Project was 'meeting an urgent need in Eastern Cape schools, for the community and for government. It is making a difference to educators' teaching abilities and habits, which, in turn, is improving learner performance' (Graven 2014b, PowerPoint slide 31).

\section{Concluding comments: implications for enhancing inclusivity}

Mathematical sense-making is the more cognitively demanding where, en route to unpacking the meaning of the mathematics, bilingual students need first to unpack the L2 text (oral or written). The often abstract and multi-semiotic nature of mathematical language adds further to the cognitive load involved. The implications are clear. Bilingual/multilingual students need to be able to access to their full linguistic repertoires to enhance their mathematical sense-making opportunities. Without this, their opportunities to maximize their academic and personal potential will be compromised.

In the South African context, only two of the country's 11 official languages are used for the Grade 12 exit examinations. These are English and Afrikaans. Considerable work was done in the early parts of last century by South Africa's Afrikaansspeaking community to ensure that their language (which evolved from Dutch) was developed to levels where it could be used for the purposes of higher learning. The Afrikaners, who were in political power at the time, wanted to make sure their children did not have to contend with the additional cognitive burden of having to learn through a L2 (English). To date, despite a number of research-based initiatives, there has been

Table 3 Ms. M's grade 4 students' average percentage scores on the South African Numeracy Chair Project's mathematical proficiency assessments (2011/2014)

\begin{tabular}{lccc}
\hline & Conceptual understanding & Strategic competence & Adaptive reasoning \\
\hline 2011 cohort & 29 & 15 & 20 \\
2014 cohort & 61 & 25 & 41 \\
Change & +32 & +10 & +21 \\
\hline
\end{tabular}

Data derived from SANCP Database 2014 
no equivalent development in achieving these same levels of academic and technical precision for the country's indigenous African languages. However ideal this would be, the perceived power of English as the language most likely to bring social and economic advantage is such that it is doubtful whether academic registers will be developed in all the African languages in the foreseeable future. This being so, it is imperative that there be sustained and systematic investment in developing strategies for ensuring that Black African children are not denied the support needed for them to become genuinely proficient in their use of the English academic register across the various curriculum areas.

Teachers need to be reassured that principled use of more than one language in the mathematics classroom is wholly appropriate, both epistemologically and pedagogically, and well-supported by research. In specific reference to South African circumstances, the stigma attached to code-switching - as illustrated by Ms. P's unease about using isiXhosa when she was 'supposed' to be using English — needs to be dispelled. Writing almost two decades ago, Setati and Adler advised that 'attention to codeswitching and its use in multilingual mathematics classrooms is an important part of a process of legitimising what teachers actually do (i.e. harness learners' main language as a resource for learning) in a context where pressure to access and acquire English is enormous' (2000, pp. 265-266).

In relation to perceptions about the power of English to provide greater access to social and economic goods, we note an 'unfortunate conflation between having opportunities to become proficient users of English and using English as the main linguistic vehicle through which to become proficient learners of mathematics' (Robertson 2017, p. 41). Many South African teachers are, like Ms. P and Ms. M, in the fortunate position of sharing a common L1 with their students. It makes no sense that advantage is not taken of this as a means of increasing students' opportunities to genuinely participate in the sense-making required for mathematics learning, and to thereby begin to narrow the 'extreme' performance gaps (Graven 2014a) that currently threaten our post-apartheid government's commitment to an inclusive education system in which injustices and inequities of the past are redressed.

In summary, bi- and multilingualism is a resource for learning that L2 students bring and it should be used as such. This said, recognizing the dominance of a particular language of learning and teaching and the access it provides to social, political and economic goods means we must simultaneously support L2 students to become proficient in this language while at the same time learning new concepts in that language. Therefore, if we want to work towards greater inclusion in our mathematics classrooms, we need to find ways for incorporating L2 teaching and learning strategies into our mathematics teachers' pedagogical repertoires.

We conclude our discussion with the following recommendations for inclusive language pedagogies in mathematics classrooms.

- As language is the main medium through which mathematics teaching and learning takes place, acquiring the requisite linguistic proficiency for meaningful participation in mathematical discussion needs to become an explicit learning goal in the mathematics classroom. Mathematics teachers need to be reassured that far from being an illicit practice, principled use of L2 students' home language represents an 
additional fund of knowledge and an essential cognitive resource for mathematical sense-making.

- Students need opportunities to engage in mathematical discussion, moving between informal and formal academic registers. They need induction into ways of engaging in exploratory talk around mathematical ideas, and they need their teachers' supportive feedback and mediation to ensure progress in their communication skills.

- Mathematics teachers need access to professional development opportunities (at both pre- and in-service levels) which clarify or, as Cummins (2015) put it 'demystify', how academic language works in the mathematics classroom. They should be encouraged to give all students access to high levels of mathematical challenge and be made aware of the risk of invalidly judging L2 students as less able.

Using multilingualism as a resource in the mathematics classroom and supporting L2 students in developing language proficiency in the main language of learning and teaching is, as we and others have noted, complex. However, each of the above, widely researched recommendations would, we argue, contribute to making mathematics teaching and learning more inclusive.

Funding information This work is based on the research supported by the South African Research Chairs Initiative of the Department of Science and Technology and National Research Foundation (Grant No. 74658). Any opinion, finding and conclusion, or recommendation expressed in this material is that of the authors and the NRF does not accept any liability in this regard.

Open Access This article is distributed under the terms of the Creative Commons Attribution 4.0 International License (http://creativecommons.org/licenses/by/4.0/), which permits unrestricted use, distribution, and reproduction in any medium, provided you give appropriate credit to the original author(s) and the source, provide a link to the Creative Commons license, and indicate if changes were made.

\section{References}

Albaugh, E. A. (2014). State-building and multilingual education in Africa. New York: Cambridge University Press.

Alidou, H., Boly, A., Brock-Utne, B., Diallo, J. S., Heugh, K., \& Wolff, H. E. (2006). Optimizing learning and education in Africa: The language factor: A stock-taking research on mother tongue and bilingual education in Sub-Saharan Africa (working document). Paris: Association for the Development of Education in Africa.

Askew, M., Rhodes, V., Brown, M., Wiliam, D., \& Johnson, D. (1997). Effective teachers of numeracy: Report of a study carried out for the teacher training agency. London: Kings College.

Barwell, R. (2016). Investigating stratification, language diversity and mathematics classroom interaction. PNA, 11(1), 34-52.

Bloch, C. (2002). A case study of Xhosa and English biliteracy in the foundation phase versus English as a 'medium of destruction'. Perspectives in Education, 20(1), 65-78.

Bourdieu, P., \& Passeron, J. C. (1977). Reproduction in education, society and culture. London: Sage.

Cammarata, L., \& Tedick, D. J. (2012). Balancing content and language in instruction: The experience of immersion teachers. The Modern Language Journal, 96(2), 251-269. https://doi.org/10.1111/j.15404781.2012.01330.x. 
Castanheira, M. L., Crawford, T., Dixon, C. N., \& Green, J. L. (2001). Interactional ethnography: An approach to studying the social construction of literate practices. Linguistics and Education, 11(4), 353-400. https://doi.org/10.1016/S0898-5898(00)00032-2.

Civil, M. (2018). Intersections of culture, language, and mathematics education: Looking back and looking ahead. In G. Kaiser, H. Forgasz, M. Graven, A. Kuzniak, E. Simmt, \& B. Xu (Eds.), Invited Lectures from the 13th International Congress on Mathematical Education (ICME-13 monographs) (pp. 31-48). Cham: Springer.

Clarkson, P. C. (2009). Mathematics teaching in Australian multilingual classrooms: Developing a relevant approach to the use of classroom languages. In R. Barwell (Ed.), Multilingualism in mathematics classrooms: Global perspectives (pp. 145-160). Bristol: Multilingual Matters.

Collier, V. P., \& Thomas, W. P. (2017). Validating the power of bilingual schooling: Thirty-two years of largescale, longitudinal research. Annual Review of Applied Linguistics, 37, 203-217. https://doi.org/10.1017 /S0267190517000034.

Cummins, J. (1994). The acquisition of English as a second language. In K. Spangenberg-Urnschat \& R. Pritchard (Eds.), Kids come in all languages: Reading instruction for ESL students (1 ${ }^{\text {th }}$ printing, 2005) (pp. 36-62). Newark, Delaware: International Reading Association.

Cummins, J. (1999). BICS and CALP: Clarifying the distinction. Washington, DC: Opinion papers. (ERIC document reproduction service no. ED 438 551).

Cummins, J. (2001). HER classic: Empowering minority students: A framework for intervention (Author's introduction; framing the universe of discourse: Are the constructs of power and identity relevant to school failure?). Harvard Educational Review, 71(4), 649-655. https://doi.org/10.17763/haer.71.4. j261357m62846812.

Cummins, J. (2005). Teaching for cross-language transfer in dual language education: Possibilities and pitfalls. TESOL symposium on dual language education: Teaching and learning two languages in the EFL setting, Bogazici Iniversity, Istanbul, Turkey. http://www.achievementseminars.com/seminar series 2005 2006/readings /tesol.Turkey.Pdf. Accessed 19 December, 2018.

Cummins, J. (2007). Bilingual and immersion programs. In M. H. Long \& C. J. Doughty (Eds.), The handbook of language teaching (pp. 161-181). Chichester: Blackwell.

Cummins, J. (2008). BICS and CALP: Empirical and theoretical status of the distinction. In B. V. Street \& N. H. Hornberger (Eds.), Encyclopedia of language and education, volume 2: Literacy (pp. 71-83). New York: Springer.

Cummins, J. (2015). How to reverse a legacy of exclusion? Identifying high-impact educational responses. Language and Education (Special issue: Language in epistemic access: mobilising multilingualism and literacy development for more equitable education in South Africa), 29(3), 272-279. https://doi. org/10.1080/09500782.2014.994528.

Cummins, J., \& Swain, M. (2014). Bilingualism in education: Aspects of theory, research and practice. London: Routledge. (original work published in 1986).

De Araujo, Z. (2017). Connections between secondary mathematics teachers' beliefs and their selection of tasks for English language learners. Curriculum inquiry, 47(4), 363-389. https://doi.org/10.1080 /03626784.2017.1368351.

Desai, Z. (1999). Enabling policies, disabling practices. Per Linguam, 15(1), 42-53. https://doi.org/10.5785 /15-1-171.

Edmonds-Wathen, C. (2017). Responding to the mathematics curriculum with language and culture. Journal of Mathematics and Culture, 11(3), 36-63.

Gervasoni, A. (2018). The impact and challenges of early mathematics intervention in an Australian context. In G. Kaiser, H. Forgasz, M. Graven, A. Kuzniak, E. Simmt, \& B. Xu (Eds.), Invited Lectures from the 13th International Congress on Mathematical Education (ICME-13 monographs) (pp. 115-133). Cham: Springer.

Graven, M. (2014a). Poverty, inequality and mathematics performance: The case of South Africa's postapartheid context. ZDM, 46(7), 1039-1049. https://doi.org/10.1007/s11858-013-0566-7.

Graven, M. (2014b). South African numeracy chair project, Rhodes University (Community of Practice Forum, august 2014, Johannesburg) [PowerPoint slides]. https://www.ru.ac.za/ media/rhodesuniversity/content/sanc/documents/COP_Presentation_9_Aug_2014.Pdf. Accessed 29 August 2019.

Graven, M. (2015). Going back in order to go forward: Recovery of mathematical foundations for intermediate phase improvement. Journal of Educational Studies, Special Issue, 1, 1-10.

Hammond, J., Burns, A., Joyce, H., Brosnan, D., \& Gerot, L. (1992). English for social purposes: A handbook for teachers of adult literacy. Sydney: National Centre for English Language Teaching and Research. 
Heugh, K. (2017). 'Lessons from Africa prove the incredible value of mother tongue learning', The Conversation (Australian edition), 27/02/2017.

Hodge, L. L., \& Cobb, P. (2019). Two views of culture and their implications for mathematics teaching and learning. Urban Education, 54(6), 860-884. https://doi.org/10.1177/0042085916641173.

Jordaan, H. (2011). Language teaching is no panacea: A theoretical perspective and critical evaluation of language in education within the South African context. South African Journal of Communication Disorders, 58(2), 79-85. https://doi.org/10.4102/sajcd.v58i2.29.

Jorgensen, R. (2018). Language resources to scaffold mathematical learning for remote indigenous learners. In R. Hunter, M. Civil, B. Herbel-Eisenmann, N. Planas, \& D. Wagner (Eds.), Mathematical discourse that breaks barriers and creates space for marginalized learners (pp. 235-255). Brill Sense: Leiden, Netherlands.

Krashen, S. D. (2009). Principles and practice in second language acquisition (internet edition). http://sdkrashen.com/Principles_and_practice/ Principles_and_practice.Pdf. Accessed 4 February, 2019. (original work published by Pergamon, 1982).

Lave, J., \& Wenger, E. (1991). Situated learning: Legitimate peripheral participation. Cambridge: Cambridge University Press.

Macdonald, C. A. (2002). Are the children still swimming up the waterfall? A look at literacy development in the new curriculum. Language Matters, 33(1), 111-141. https://doi.org/10.1080/10228190208566181.

McAuliffe, M., \& Ruhs, M. (2017). Making sense of migration in an increasingly interconnected world. In M. McAuliffe \& M. Ruhs (Eds.), World migration report 2018 (pp. 1-9). Geneva: International Organization for Migration.

Meaney, T., Trinick, T., \& Fairhall, U. (2017). Language choice and ethnomathematics in the Pacific: Transforming education? Journal of Mathematics and Culture, 11(3), 112-132.

Melikoff, O. (2018). The St. Lambert experiment in French immersion revisited: Fifty years later. https:/olgamelikoff.com/the-st-lambert-experiment-in-french-immersion-revisited-fifty-years-later/. Accessed 5 August 2019.

Mercer, N., \& Howe, C. (2012). Explaining the dialogic processes of teaching and learning: The value and potential of sociocultural theory. Learning, Culture and Social Interaction, 1(1), 12-21. https://doi. org/10.1016/j.lcsi.2012.03.001.

Moll, L. C. (1992). Bilingual classroom studies and community analysis: Some recent trends. Educational Researcher, 21(2), 20-24. https://doi.org/10.2307/1176576.

Moll, L. C. (2015). Tapping into the "hidden" home and community resources of students. Kappa Delta Pi Record, 51(3), 114-117. https://doi.org/10.1080/00228958.2015.1056661.

Morrow, W. (1994). Entitlement and achievement in education. Studies in Philosophy and Education, 13(1), 33-47. https://doi.org/10.1007/bf01074084.

Moschkovich, J. (2010). Language(s) and learning mathematics: Resources, challenges and issues for research. In J. Moschkovich (Ed.), Language and mathematics: Multiple perspectives and directions for research (pp. 1-28). Charlotte (NC): Information Age Publishing.

National Research Council. (2001). Adding it up: Helping children learn mathematics. In J. Kilpatrick, J. Swafford, \& B. Findell (Eds.), Mathematics Learning Study Committee, Center for Education, Division of Behavioral and Social Sciences and Education. Washington, DC: National Academy Press.

Planas, N. (2018). Language as resource: A key notion for understanding the complexity of mathematics learning. Educational Studies in Mathematics, 98(3), 215-229. https://oi.org/10.1007/s10649-018-9810y.

Planas, N., \& Setati-Phakeng, M. (2014). On the process of gaining language as a resource in mathematics education. ZDM, 46(6), 883-893. https://doi.org/10.1007/s11858-014-0610-2.

Prediger, S. (2019). Investigating and promoting teachers' expertise for language-responsive mathematics teaching. Mathematics Education Research Journal, 31, 367-392. https://doi.org/10.1007/s13394-01900258-1.

Prediger, S., Erath, K., \& Moser Opitz, E. (2019). Language challenges for students with mathematics difficulties: An overview on research results and instructional approaches. In A. Fritz, V. Haase, \& P. R s nen (Eds.), International handbook of math learning difficulties: From the laboratory to the classroom (pp. 437-455). Cham: Springer.

Probyn, M. (2009). 'Smuggling the vernacular into the classroom': Conflicts and tensions in classroom codeswitching in township/rural schools in South Africa. International Journal of Bilingual Education and Bilingualism, 12(2), 123-136. https://doi.org/10.1080/13670050802153137.

Probyn, M. (2015). Pedagogical translanguaging: Bridging discourses in south African science classrooms. Language and Education, 29(3), 218-234. https://doi.org/10.4324/9781315229744-4. 
Reddy, V., Isdale, K., Juan, A., Visser, M., Winnaar, L., \& Arends, F. (2016). TIMSS 2015: Highlights of mathematics achievement of grade 5 south African learners. Pretoria: Department of Basic Education/ Human Sciences Research Council.

Robertson, S.-A. (2017). The place of language in supporting children's mathematical development: Grade 4 teachers' use of classroom talk. Rhodes University, Grahamstown: Unpublished doctoral thesis.

Robertson, S.-A., \& Graven, M. (2015). Exploring south African mathematics teachers' experiences of learner migration. Intercultural Education (Special Issue: “Intercultural Mathematics Education”), 26(4), 278295. https://doi.org/10.1080/14675986.2015.1071754.

Robertson, S.-A., \& Graven, M. (2018). A teacher's challenge in developing mathematics talk for sensemaking in and through a second language. In J. Hunter, P. Perger, \& L. Darragh (Eds.), Making waves, opening spaces (Proceedings of the 41st annual conference of the Mathematics Education Research Group of Australasia) (p. 757). Auckland: MERGA.

Robertson, S.-A., \& Graven, M. (2019a). Yes, it is 'immersion' of a sort, but not one that conduces to mathematical sense-making. In G. Hine, S. Blackley, \& A. Cooke (Eds.), Mathematics education research: Impacting practice (Proceedings of the 42nd annual conference of the Mathematics Education Research Group of Australasia) (pp. 604-611). Perth: MERGA.

Robertson, S.-A., \& Graven, M. (2019b). Exploratory mathematics talk in a second language: A sociolinguistic perspective. Educational Studies in Mathematics, 101(2), 215-232. https://doi.org/10.1007 /s10649-018-9840-5.

Ruíz, R. (1984). Orientations in language planning. NABE Journal, 8(2), 15-34. https://doi.org/10.1080 /08855072.1984.10668464.

Setati, M., \& Adler, J. (2000). Between languages and discourses: Language practices in primary multilingual mathematics classrooms in South Africa. Educational Studies in Mathematics, 43(3), 243-269.

Setati, M., Chitera, N., \& Essien, A. (2009). Research on multilingualism in mathematics education in South Africa: 2000-2007. African Journal of Research in Mathematics, Science and Technology Education, 13(sup1), 65-80. https://doi.org/10.1080/10288457.2009.10740662.

Sibanda, L. (2017). Grade 4 learners' linguistic difficulties in solving mathematical assessments. African Journal of Research in Mathematics, Science and Technology Education, 21(1), 86-96. https://doi. org/10.1080/18117295.2017.1291476.

Sibanda, L., \& Graven, M. (2018). Can mathematics assessments be considered valid if learners fail to access what is asked of them? South African Journal of Childhood Education, 8(1), 1-12. https://doi. org/10.4102/sajce.v8i1.505.

Skutnabb-Kangas, T., \& McCarty, T. L. (2008). Key concepts in bilingual education: Ideological, historical, epistemological, and empirical foundations. In N. H. Hornberger (Ed.), Encyclopedia of language and education: Volume 5: Bilingual education (pp. 3-17). Boston: Springer.

Skutnabb-Kangas, T. (1990). Language, literacy and minorities. London: Minority Rights Group.

South Africa, Department of Basic Education. (2010). The status of the language of learning and teaching in south African public schools: A qualitative overview. Pretoria: Government Printer.

South Africa, Department of Basic Education. (2014). Report on the annual National Assessments of 2014: Grades 1 to 6 and 9. Pretoria: Government Printer.

South Africa, Department of Education. (1997). Language in education policy. Pretoria: Government Printer.

South Africa, Department of Education. (2001). Education white paper 6: Special needs education: Building an inclusive education and training system. Pretoria: Government Printer.

Spaull, N. (2019). 'Priorities for education reform in South Africa' (input document for Treasury's economic colloquium 19 January 2019). https://nicspaull.files.wordpress.com/ 2019/01/v2-spaull-priorities-foreduc-reform-treasury-19-jan-2019.Pdf. Accessed 7 August 2019.

Statistics South Africa (2019a). Five facts about poverty in South Africa http://www.statssa.gov.za/?p=12075. Accessed 19 August 2019.

Statistics South Africa (2019b). The extent of food security in South Africa. http://www.statssa.gov. $\mathrm{za} / \mathrm{p}=12135$. Accessed 19 August 2019.

Swain, M. (1985). Communicative competence: Some roles of comprehensible input and comprehensible output in its development. In S. M. Gass \& C. G. Madden (Eds.), Input in second language acquisition (pp. 235-253). Rowley, MA: Newbury House.

Swain, M. (2006). Languaging, agency and collaboration in advanced second language proficiency. In H. Byrnes (Ed.), Advanced language learning: The contribution of Halliday and Vygotsky (pp. 95-108). New York: Continuum.

Swain, M., \& Lapkin, S. (2013). A Vygotskian sociocultural perspective on immersion education: The L1/L2 debate. Journal of Immersion and Content-Based Language Education, 1(1), 101-129. https://doi. org/10.1075/jicb.1.1.05swa. 
UNESCO (United Nations Educational, Scientific and Cultural Organization) Global Education Monitoring Report. (2016). Policy paper 24: If you don't understand, how can you learn? Paris: UNESCO.

United Nations. (2018). The sustainable development goals report: 2018. New York: United Nations.

Westaway, L. (2019). The role of reflexivity in the emergence and expression of teachers' identities in teaching primary school mathematics. ZDM, 51(3), 481-492. https://doi.org/10.1007/s11858-019-01042-y.

Westaway, L., \& Graven, M. (2019). Exploring grade 3 teachers' resistance to 'take up' progressive mathematics teaching roles. Mathematics Education Research Journal, 31(1), 27-46. https://doi. org/10.1007/s13394-018-0237-7.

Publisher's note Springer Nature remains neutral with regard to jurisdictional claims in published maps and institutional affiliations. 